Research Paper

\title{
A Survey of the FAERS Database Concerning the Ad- verse Event Profiles of $\alpha$ I-Adrenoreceptor Blockers for Lower Urinary Tract Symptoms
}

Koji Yoshimura 1, Kaori Kadoyama 2, Toshiyuki Sakaeda ${ }^{2}{ }^{\bowtie}$, Yoshio Sugino ${ }^{1}$, Osamu Ogawa ${ }^{1}$, and Yasushi Okuno ${ }^{3 凶}$

1. Department of Urology, Kyoto University Graduate School of Medicine, Kyoto, Japan;

2. Center for Integrative Education in Pharmacy and Pharmaceutical Sciences, Kyoto University Graduate School of Pharmaceutical Sciences, Kyoto, Japan;

3. Department of Systems Biosciences for Drug Discovery, Kyoto University Graduate School of Pharmaceutical Sciences, Kyoto, Japan.

$\triangle$ Corresponding author: Toshiyuki Sakaeda, Ph.D., Center for Integrative Education in Pharmacy and Pharmaceutical Sciences, Graduate School of Pharmaceutical Sciences, Kyoto University, Kyoto 606-8501, Japan, Tel: +81-75-753-9560, Fax: +81-75-753-9253, e-mail: sakaedat@pharm.kyoto-u.ac.jp; Yasushi Okuno, Ph.D., Department of Systems Biosciences for Drug Discovery, Graduate School of Pharmaceutical Sciences, Kyoto University, Kyoto 606-8501, Japan, Tel\&Fax: +81-75-753-4559, e-mail: okuno@pharm.kyoto-u.ac.jp.

(C) Ivyspring International Publisher. This is an open-access article distributed under the terms of the Creative Commons License (http://creativecommons.org/ licenses/by-nc-nd/3.0/). Reproduction is permitted for personal, noncommercial use, provided that the article is in whole, unmodified, and properly cited.

Received: 2013.0I.17; Accepted: 2013.05.05; Published: 2013.05.15

\begin{abstract}
Purpose: Current guidelines recommend $\alpha \mathrm{I}$-adrenoreceptor blockers (AIBs) for treating lower urinary tract symptoms suggestive of benign prostatic hyperplasia, but their adverse effects can be problematic. In this study, reports submitted to the US Food and Drug Administration Adverse Event Reporting System (FAERS) between 1997 and 2011 were reviewed to assess the safety profiles of AIBs.

Methods: After deleting duplicated submissions and revising arbitrary drug names, reports involving AIBs for male patients were analyzed. Data mining algorisms were used for the quantitative detection of signals, where a signal represents an association between a drug and an adverse event or a drug-associated adverse event, including the proportional reporting ratio, reporting odds ratio, information component given by a Bayesian confidence propagation neural network, and empirical Bayes geometric mean.

Results: The total number of reports used was $1,260,182$. Signal scores suggested the associations of alfuzosin, doxazosin, tamsulosin, and terazosin with dizziness/vertigo, orthostatic hypotension, erectile dysfunction, ejaculation dysfunction (EjD), thirst/dry mouth, and constipation; however, reports on naftopidil, silodosin, and urapidil were not enough to compare with the other 4 AIBs. Signal scores for EjD were higher for tamsulosin, and those for dizziness/vertigo were lower for doxazosin than for the other 3 drugs.

Conclusions: Tamsulosin-associated $\mathrm{EjD}$, which was found in clinical studies, was reproduced in this analysis with markedly higher signal scores, and these results strongly suggest the necessity of well-organized clinical studies on AIB-associated adverse events.
\end{abstract}

Key words: adverse events, FAERS, a1 blockers, pharmacoepidemiology.

\section{Introduction}

a1-Adrenoreceptor blockers (A1Bs) are used worldwide to relieve obstructive urinary symptoms, especially by men with benign prostatic hyperplasia
$(\mathrm{BPH})$, as many guidelines recommend the usage of A1Bs as a first line therapy for moderate to severe lower urinary tract symptoms (LUTS) suggestive of 
$\mathrm{BPH}$ [1-3]. The latest version of the guidelines on the management of BPH from the American Urological Association [1] and the guidelines on the management of male LUTS from the European Urological Association [2] refer to four A1Bs, alfuzosin, doxazosin, tamsulosin, and terazosin, while the Japanese guidelines for BPH also recommend naftopidil and silodosin [3]. These recommendations are based on clinical evidence; however, relatively few reports are available for their safety profiles.

Early developed A1Bs, i.e., alfuzosin, doxazosin, and terazosin, were shown to lack a1-adrenoreceptor subtype selectivity [4], and are supposed to induce vascular adverse events, such as orthostatic hypotension. In contrast, recently developed A1Bs show a1-adrenoreceptor subtype selectivity, i.e., tamsulosin (a1a and a1d-selective), naftopidil (a1d-selective), and silodosin (a1a-selective) [4], and these are thought to result in a relatively low incidence of vascular adverse events than that of the early developed A1Bs. A recently published meta-analysis concluded that asthenia/fatigue, dizziness, and hypotension were more pronounced for doxazosin and terazosin than for tamsulosin [5]; however, the same analysis indicated that alfuzosin developed these adverse events on the same level as that of tamsulosin, suggesting that the safety profiles of A1Bs cannot be explained only by in vitro a1-adrenoreceptor subtype selectivity.

$\mathrm{BPH}$ is a commonly reported disease in older men that can lead to LUTS, and male sexual dysfunction, e.g., decreased libido, erectile dysfunction (ED) and ejaculation dysfunction $(\mathrm{EjD})$, is also age-related [6]. Epidemiological studies have confirmed a link between BPH/LUTS and sexual dysfunction in older men, which is independent of age and cardiovascular co-morbidities [6]. Various treatments with drugs for $\mathrm{BPH} /$ LUTS may affect sexuality, with differences being observed between drug classes and between drugs within the same class $[6,7]$. The treatments with A1Bs are generally thought to have a beneficial effect on decreased libido and ED, whereas their impact on EjD varies among A1Bs [7]. The safety profiles of A1Bs vary across previous reports, and their comparisons in the same study are quite limited.

In this study, adverse event reports submitted to the US Food and Drug Administration (FDA) [8] were reviewed to assess the adverse event profiles of 7 A1Bs; alfuzosin, doxazosin, tamsulosin, terazosin, naftopidil, silodosin, and urapidil. Data mining algorithms were used for the quantitative detection of signals [9-18], in which a signal represents an association between a drug and an adverse event or a drug-associated adverse event. The adverse events analyzed included dizziness/vertigo, orthostatic hypotension, ED, EjD, thirst/dry mouth, constipation, and diarrhea.

\section{Methods}

\section{Data sources}

Input data were taken from the public release of the FDA's Adverse Event Reporting System (FAERS, formerly AERS) database [8], which covers the period from the fourth quarter of 1997 through to the third quarter of 2011. The total number of reports used was $4,671,217$. Besides those from manufacturers, reports can be submitted from health care professionals and the public. Its structure adheres to the international safety reporting guidance issued by the International Conference on Harmonisation, ICH E2B [19]. A data set consists of 7 data tables; patient demographic and administrative information (DEMO), drug/biologic information (DRUG), adverse events (REAC), patient outcomes (OUTC), report sources (RPSR), drug therapy start and end dates (THER), and indications for use/diagnosis (INDI). Adverse events and medication errors are coded using the preferred terms (PTs) in the Medical Dictionary for Regulatory Activities (MedDRA) terminology [20], with version 15.1 being used in this study.

Prior to data mining, duplicated reports were deleted according to the FDA's recommendation of adopting the most recent CASE number, resulting in a reduction in the number of reports from 4,671,217 to $3,472,494$. All drug names were unified into generic names by a text-mining approach, because the FAERS permits the registering of arbitrary drug names, including trade names and abbreviations. Spelling errors were detected by the spell checker software, GNU Aspell, and were carefully confirmed by working pharmacists. Foods, beverages, treatments (e.g. $X$-ray radiation), and unspecified names (e.g. beta-blockers) were omitted for this study. In this study, reports of females and those without gender data were deleted; therefore, the total number of reports used was 1,260,182. Consequently, a total of $19,184,590$ co-occurrences were found in 1,260,182 reports, where a co-occurrence was a pair of a drug and an adverse event, and they were the basis for signal detection.

\section{Definition of adverse events}

According to the MedDRA ver. 15.1, constipation, diarrhea, and orthostatic hypotension were coded as PT10010774, PT10012735, and PT10031127, respectively. Adverse events coded by PT10043458 (thirst) and PT10013781 (dry mouth) were defined as 
thirst/dry mouth; those coded by PT10013573 (dizziness), PT10013576 (dizziness exertional), PT10013578 (dizziness postural), PT10047340 (vertigo), PT10047343 (vertigo central nervous system origin), PT10047344 (vertigo labyrinthine), PT10047348 (vertigo positional), and PT10066964 (procedural dizziness), as dizziness/vertigo; those coded by PT10052004 (organic erectile dysfunction), PT10052005 (psychogenic erectile dysfunction), and PT10061461 (erectile dysfunction), as ED; and those coded by PT10014325 (ejaculation delayed), PT10014326 (ejaculation disorder), PT10014328 (ejaculation failure), PT10059013 (nocturnal emission), and PT10038967 (retrograde ejaculation), as EjD.

\section{Data Mining}

Data mining algorithms have been developed to identify drug-associated adverse events (signals) that are reported more frequently than expected by estimating expected reporting frequencies on the basis of information on all drugs and all events in the database [13-18]. For example, the proportional reporting ratio (PRR) [9], the reporting odds ratio (ROR) [10], the information component (IC) [11], and the empirical Bayes geometric mean (EBGM) [12] are widely used, and indeed, currently employed by the Medicines and Healthcare products Regulatory Agency (MHRA), UK, the Netherlands Pharmacovigilance Centre, the World Health Organization (WHO), and the FDA, respectively. All of these algorithms calculate signal scores, i.e., values for PRR, ROR, IC, and EBGM, to assess whether a drug is significantly associated with an adverse event or not from a two-by-two frequency table of counts. However, these calculations or algorithms, so-called disproportionality analyses or measures, differ from one another in that the PRR and ROR are frequentist (non-Bayesian), whereas the IC and EBGM are Bayesian.

In this section, only the scoring thresholds are given. The reader is referred to previous articles for more extensive details on each statistical test [9-12]. Using the PRR, a signal is detected if the number of co-occurrences is 3 or more and the PRR is 2 or more with an associated $\chi 2$ value of 4 or more [9]. For the ROR, a signal is detected, if the lower limit of the $95 \%$ two-sided confidence interval exceeds 1 [10]. Signal detection using the IC is done using the IC025 metric, a lower limit of the 95\% two-sided confidence interval of the IC, and a signal is detected if the IC025 value exceeds 0 [11]. Finally, for the EBGM, the EB05 metric, a lower one-sided $95 \%$ confidence limit of the EBGM, is used and a signal is detected when the EB05 is greater than or equal to the threshold value 2.0 [12].

\section{Results}

The total number of co-occurrences with alfuzosin was 12,992, and 48,001 for doxazosin, 2,084 for naftopidil, 1,934 for silodosin, 82,799 for tamsulosin, 34,011 for terazosin, and 3,845 for urapidil. The values for naftopidil, silodosin, and urapidil were not large enough to compare with the other 4 A1Bs. Table 1 lists the signal scores for alfuzosin-, doxazosin-, tamsulosin-, and terazosin-associated dizziness/vertigo and orthostatic hypotension, with those for ED and EjD being listed in Table 2 and those for thirst/dry mouth and constipation being listed in Table 3. The scores indicated significant associations of 4 A1Bs with these adverse events. The scores for dizziness/vertigo were the lowest for doxazosin, whereas they were similar among the 4 A1Bs for orthostatic hypotension (Table 1). No significant differences in scores were observed among the 4 A1Bs for $\mathrm{ED}$, while those for $\mathrm{EjD}$ were markedly higher for tamsulosin than for the other A1Bs (Table 2). The scores indicated that associations with thirst/dry mouth and constipation were marginal (Table 3), and associations with diarrhea were not significant (data not shown).

\section{Discussion}

Dizziness/vertigo and orthostatic hypotension are important vascular adverse events for A1B users. A meta-analysis suggested that vascular adverse events were more pronounced for doxazosin (conventional standard formulation) and terazosin than for alfuzosin and tamsulosin [5]. This analysis also suggested that the gastrointestinal therapeutic system (GITS), i.e., controlled-release formulation, may affect the safety profiles of doxazosin [5]. In this study, these 4 A1Bs were shown to be associated with dizziness/vertigo and orthostatic hypotension (Table 1). Additionally, the signal scores suggested differences among the A1Bs in terms of susceptibility to these events; however, the position of doxazoin in the rank-order of scores was lower than that of the meta-analysis. Doxazosin is often prescribed for patients with hypertension. Sub-analysis after stratification according to indication or formulation may resolve this discrepancy.

A1Bs for $\mathrm{BPH}$ are generally recognized to have a beneficial effect on sexual dysfunction, especially ED [7]. An improvement in ED by A1Bs has been reported by several clinical studies [21-24], although this effect was not always observed [25-27]. As shown in Table 2, the signal scores suggested significant associations of A1Bs with ED, but associations were barely detectable. This suggests that A1Bs have only 
slight effects on ED, if any. The signal scores were larger for EjD than for ED, with a markedly higher value being observed for tamsulosin (Table 2). Tamsulosin, and a higher level of silodosin, can increase the risk of $\operatorname{EjD}[6,7,28-31]$, and these findings in clinical studies were reproduced in this analysis.
Tamsulosin and silodosin selectively antagonize the ala adrenereceptor subtype [4], which is widely distributed in organs including in the emission phase of ejaculation, and this is a potential explanation for the high risk of EjD [6].

Table I. Alfuzosin-, doxazosin-, tamsulosin-, and terazosin-associated dizziness/vertigo and orthostatic hypotension.

\begin{tabular}{|c|c|c|c|c|c|}
\hline & $\mathrm{N}$ & $\begin{array}{l}\text { PRR } \\
\left(x^{2}\right)\end{array}$ & $\begin{array}{l}\text { ROR } \\
\text { (95\% two-sided CI) }\end{array}$ & $\begin{array}{l}\text { IC } \\
\text { (95\% two-sided CI) }\end{array}$ & $\begin{array}{l}\text { EBGM } \\
\text { ( } 95 \% \text { one-sided CI) }\end{array}$ \\
\hline \multicolumn{6}{|l|}{ dizziness/vertigo } \\
\hline alfuzosin & 249 & $\begin{array}{l}2.74^{*} \\
(267.4)\end{array}$ & $\begin{array}{l}2.74^{*} \\
(2.42,3.06)\end{array}$ & $\begin{array}{l}1.42^{*} \\
(1.24,1.60)\end{array}$ & $\begin{array}{l}2.66^{*} \\
(2.39)\end{array}$ \\
\hline doxazosin & 427 & $\begin{array}{l}1.26 \\
(22.0)\end{array}$ & $\begin{array}{l}1.26^{*} \\
(1.14,1.37)\end{array}$ & $\begin{array}{l}0.32^{*} \\
(0.19,0.46)\end{array}$ & $\begin{array}{l}1.25 \\
(1.15)\end{array}$ \\
\hline tamsulosin & 1305 & $\begin{array}{l}2.24^{*} \\
(886.2)\end{array}$ & $\begin{array}{l}2.25^{*} \\
(2.13,2.37)\end{array}$ & $\begin{array}{l}1.15^{*} \\
(1.07,1.23)\end{array}$ & $\begin{array}{l}2.22^{*} \\
(2.12)\end{array}$ \\
\hline terazosin & 636 & $\begin{array}{l}2.67^{*} \\
(650.2)\end{array}$ & $\begin{array}{l}2.68^{*} \\
(2.47,2.88)\end{array}$ & $\begin{array}{l}1.39^{*} \\
(1.28,1.51)\end{array}$ & $\begin{array}{l}2.62^{*} \\
(2.45)\end{array}$ \\
\hline \multicolumn{6}{|c|}{ orthostatic hypotension } \\
\hline alfuzosin & 45 & $\begin{array}{l}4.20^{*} \\
(106.3)\end{array}$ & $\begin{array}{l}4.21^{*} \\
(3.14,5.28)\end{array}$ & $\begin{array}{l}1.95^{*} \\
(1.53,2.38)\end{array}$ & $\begin{array}{l}3.83^{*} \\
(2.90)\end{array}$ \\
\hline doxazosin & 105 & $\begin{array}{l}2.65^{*} \\
(106.3)\end{array}$ & $\begin{array}{l}2.66^{*} \\
(2.20,3.13)\end{array}$ & $\begin{array}{l}1.37^{*} \\
(1.10,1.65)\end{array}$ & $\begin{array}{l}2.54^{*} \\
(2.16)\end{array}$ \\
\hline tamsulosin & 224 & $\begin{array}{l}3.28^{*} \\
(353.1)\end{array}$ & $\begin{array}{l}3.31^{*} \\
(2.90,3.72)\end{array}$ & $\begin{array}{l}1.69^{*} \\
(1.50,1.88)\end{array}$ & $\begin{array}{l}3.20^{*} \\
(2.86)\end{array}$ \\
\hline terazosin & 170 & $\begin{array}{l}6.07^{*} \\
(712.9)\end{array}$ & $\begin{array}{l}6.13^{*} \\
(5.27,6.99)\end{array}$ & $\begin{array}{l}2.55^{*} \\
(2.33,2.77)\end{array}$ & $\begin{array}{l}6.02^{*} \\
(5.29)\end{array}$ \\
\hline
\end{tabular}

$\mathrm{N}$ : the number of co-occurrences, PRR: the proportional reporting ratio, ROR: the reporting odds ratio, IC: the information component, EBGM: the empirical Bayes geometric mean. *: signal detected.

Table 2. Alfuzosin-, doxazosin-, tamsulosin-, and terazosin-associated erectile dysfunction and ejaculation dysfunction.

\begin{tabular}{|c|c|c|c|c|c|}
\hline & $\mathrm{N}$ & $\begin{array}{l}\text { PRR } \\
\left(\mathrm{X}^{2}\right)\end{array}$ & $\begin{array}{l}\text { ROR } \\
(95 \% \text { two-sided CI) }\end{array}$ & $\begin{array}{l}\text { IC } \\
\text { (95\% two-sided CI) }\end{array}$ & $\begin{array}{l}\text { EBGM } \\
\text { ( } 95 \% \text { one-sided CI) }\end{array}$ \\
\hline \multicolumn{6}{|c|}{ erectile dysfunction } \\
\hline alfuzosin & 33 & $\begin{array}{l}1.76 \\
(10.1)\end{array}$ & $\begin{array}{l}1.76^{*} \\
(1.25,2.27)\end{array}$ & $\begin{array}{l}0.76^{*} \\
(0.27,1.25)\end{array}$ & $\begin{array}{l}1.64 \\
(1.23)\end{array}$ \\
\hline doxazosin & 182 & $\begin{array}{l}2.63^{*} \\
(182.7)\end{array}$ & $\begin{array}{l}2.65^{*} \\
(2.29,3.00)\end{array}$ & $\begin{array}{l}1.38^{*} \\
(1.17,1.59)\end{array}$ & $\begin{array}{l}2.57^{*} \\
(2.27)\end{array}$ \\
\hline tamsulosin & 240 & $\begin{array}{l}2.01^{*} \\
(121.3)\end{array}$ & $\begin{array}{l}2.02^{*} \\
(1.78,2.26)\end{array}$ & $\begin{array}{l}1.00^{*} \\
(0.81,1.18)\end{array}$ & $\begin{array}{l}1.98 \\
(1.78)\end{array}$ \\
\hline terazosin & 129 & $\begin{array}{l}2.64^{*} \\
(129.0)\end{array}$ & $\begin{array}{l}2.64^{*} \\
(2.22,3.06)\end{array}$ & $\begin{array}{l}1.37^{*} \\
(1.12,1.62)\end{array}$ & $\begin{array}{l}2.55^{*} \\
(2.20)\end{array}$ \\
\hline \multicolumn{6}{|c|}{ ejaculation dysfunction } \\
\hline alfuzosin & 15 & $\begin{array}{l}4.34^{*} \\
(35.3)\end{array}$ & $\begin{array}{l}4.35^{*} \\
(2.62,6.08)\end{array}$ & $\begin{array}{l}1.80^{*} \\
(1.08,2.52)\end{array}$ & $\begin{array}{l}3.26 \\
(1.97)\end{array}$ \\
\hline doxazosin & 41 & $\begin{array}{l}3.21^{*} \\
(60.3)\end{array}$ & $\begin{array}{l}3.23^{*} \\
(2.37,4.08)\end{array}$ & $\begin{array}{l}1.59^{*} \\
(1.15,2.03)\end{array}$ & $\begin{array}{l}2.87^{*} \\
(2.20)\end{array}$ \\
\hline tamsulosin & 292 & $\begin{array}{l}13.29^{*} \\
(3310.1)\end{array}$ & $\begin{array}{l}14.04^{*} \\
(12.47,15.61)\end{array}$ & $\begin{array}{l}3.67^{*} \\
(3.50,3.84)\end{array}$ & $\begin{array}{l}13.21^{*} \\
(11.99)\end{array}$ \\
\hline terazosin & 23 & $\begin{array}{l}2.54^{*} \\
(20.0)\end{array}$ & $\begin{array}{l}2.55^{*} \\
(1.69,3.41)\end{array}$ & $\begin{array}{l}1.23^{*} \\
(0.64,1.81)\end{array}$ & $\begin{array}{l}2.17 \\
(1.53)\end{array}$ \\
\hline
\end{tabular}

$\mathrm{N}$ : the number of co-occurrences, PRR: the proportional reporting ratio, ROR: the reporting odds ratio, IC: the information component, EBGM: the empirical Bayes geometric mean. *: signal detected. 
Table 3. Alfuzosin-, doxazosin-, tamsulosin-, and terazosin-associated thirst/dry mouth and constipation.

\begin{tabular}{|c|c|c|c|c|c|}
\hline & $\mathrm{N}$ & $\begin{array}{l}\text { PRR } \\
\left(x^{2}\right)\end{array}$ & $\begin{array}{l}\text { ROR } \\
\text { (95\% two-sided CI) }\end{array}$ & $\begin{array}{l}\text { IC } \\
\text { (95\% two-sided CI) }\end{array}$ & $\begin{array}{l}\text { EBGM } \\
\text { ( } 95 \% \text { one-sided CI) }\end{array}$ \\
\hline \multicolumn{6}{|l|}{ thirst/dry mouth } \\
\hline alfuzosin & 28 & $\begin{array}{l}1.58 \\
(5.4)\end{array}$ & $\begin{array}{l}1.58^{*} \\
(1.09,2.07)\end{array}$ & $\begin{array}{l}0.61^{*} \\
(0.07,1.14)\end{array}$ & $\begin{array}{l}1.47 \\
(1.08)\end{array}$ \\
\hline doxazosin & 137 & $\begin{array}{l}2.09^{*} \\
(77.2)\end{array}$ & $\begin{array}{l}2.10^{*} \\
(1.77,2.42)\end{array}$ & $\begin{array}{l}1.05^{*} \\
(0.81,1.29)\end{array}$ & $\begin{array}{l}2.04 \\
(1.77)\end{array}$ \\
\hline tamsulosin & 196 & $\begin{array}{l}1.74 \\
(60.5)\end{array}$ & $\begin{array}{l}1.74^{*} \\
(1.51,1.97)\end{array}$ & $\begin{array}{l}0.79^{*} \\
(0.58,0.99)\end{array}$ & $\begin{array}{l}1.71 \\
(1.52)\end{array}$ \\
\hline terazosin & 111 & $\begin{array}{l}2.40^{*} \\
(88.7)\end{array}$ & $\begin{array}{l}2.40^{*} \\
(1.99,2.81)\end{array}$ & $\begin{array}{l}1.23^{*} \\
(0.96,1.50)\end{array}$ & $\begin{array}{l}2.31 \\
(1.97)\end{array}$ \\
\hline \multicolumn{6}{|l|}{ constipation } \\
\hline alfuzosin & 42 & $\begin{array}{l}1.06 \\
(0.1)\end{array}$ & $\begin{array}{l}1.06 \\
(0.78,1.33)\end{array}$ & $\begin{array}{l}0.06 \\
(-0.37,0.49)\end{array}$ & $\begin{array}{l}1.03 \\
(0.80)\end{array}$ \\
\hline doxazosin & 177 & $\begin{array}{l}1.21 \\
(6.0)\end{array}$ & $\begin{array}{l}1.21^{*} \\
(1.04,1.37)\end{array}$ & $\begin{array}{l}0.26^{*} \\
(0.05,0.48)\end{array}$ & $\begin{array}{l}1.20 \\
(1.06)\end{array}$ \\
\hline tamsulosin & 351 & $\begin{array}{l}1.39 \\
(37.4)\end{array}$ & $\begin{array}{l}1.39^{*} \\
(1.25,1.53)\end{array}$ & $\begin{array}{l}0.47^{*} \\
(0.31,0.62)\end{array}$ & $\begin{array}{l}1.38 \\
(1.26)\end{array}$ \\
\hline terazosin & 168 & $\begin{array}{l}1.62 \\
(38.8)\end{array}$ & $\begin{array}{l}1.62^{*} \\
(1.39,1.85)\end{array}$ & $\begin{array}{l}0.68^{*} \\
(0.46,0.90)\end{array}$ & $\begin{array}{l}1.59 \\
(1.40)\end{array}$ \\
\hline
\end{tabular}

$\mathrm{N}$ : the number of co-occurrences, PRR: the proportional reporting ratio, ROR: the reporting odds ratio, IC: the information component, EBGM: the empirical Bayes geometric mean. *: signal detected.

Gastrointestinal adverse events do not attract much attention for A1Bs. The signal scores suggested that A1Bs had potential associations with thirst/dry mouth and constipation, but these associations were marginal and depended on the data mining methods (Table 3). However, many patients treated with A1Bs were noted to have persistent storage symptoms [32]. Although the current guidelines recommended A1Bs and 5-a reductase inhibitors, either alone or in combination, for BPH/LUTS, the additional use of antimuscarinic drugs may be an option in the near future [32]. Gastrointestinal adverse events caused by antimuscarinic drugs can be problematic; however, data on efficacy and safety after long-term use are not available [32]. Assessing the safety profiles of antimuscarinic drugs using the FAERS database may provide useful information for the management of patients with BPH/LUTS.

Data mining of the FAERS database has several limitations. First, adverse events are underreported [18]. Even though the reporting rate has markedly improved, the FAERS database is still not appropriate for estimating incidence rates, due to the absence of a denominator. Second, data occasionally contain misspelling and miswords, and there are also a number of duplicate entries [13]. These problems were resolved in the present study, prior to the analysis. Third, the system was started more than 10 years ago, and reporting patterns, especially the PTs of MedDRA, have changed over time [13]. Fourth, sig- nal scores are influenced by various factors, especially when it comes to recently launched drugs [18]. Fifth, it should be noted that there is no credible counterfactual means, e.g., a randomized control group, to list drug-associated adverse events (signals); therefore, disease-oriented adverse events can be listed as signals [18].

In conclusion, reports in the FAERS database were reviewed to assess the safety profiles of A1Bs. From 1,260,182 reports for male patients between 1997 and 2011, alfuzosin, doxazosin, tamsulosin, and terazosin were associated with dizziness/vertigo, orthostatic hypotension, ED, EjD, thirst/dry mouth, and constipation. Tamsulosin-associated EjD, which was found in clinical studies, was reproduced in this analysis with markedly higher signal scores, and these results strongly suggest the necessity of well-organized clinical studies on A1B-associated adverse events.

\section{Abbreviations}

A1Bs: a1-adrenoreceptor blockers; FAERS: FDA Adverse Event Reporting System; BPH: benign prostatic hyperplasia; EBGM: empirical Bayes geometric mean; ED: erectile dysfunction; EjD: ejaculation dysfunction; FDA: Food and Drug Administration; IC: information component; LUTS: lower urinary tract symptoms; MedDRA: Medical Dictionary for Regulatory Activities; PRR: proportional reporting ratio; PT: preferred term; ROR: reporting odds ratio. 


\section{Acknowledgements}

This study was partially supported by the Funding Program for Next Generation World-Leading Researchers.

\section{Competing Interests}

The authors have declared that no competing interest exists.

\section{References}

1. McVary KT, Roehrborn CG, Avins AL, et al. Update on AUA guideline on the management of benign prostatic hyperplasia. J Urol. 2011; 185: 1793-1803.

2. [Internet] Oelke M, Bachmann A, Descazeaud A, et al. Guidelines on the treatment of non-neurogenic male LUTS. http://www.uroweb.org/ gls/pdf/12_Male_LUTS_LR\%20May\%209th\%202012.pdf

3. Homma Y, Gotoh M, Yokoyama $\mathrm{O}$, et al. Outline of JUA clinical guidelines for benign prostatic hyperplasia. Int J Urol. 2011; 18: 741-756.

4. Roehrborn CG, Schwinn DA. Alpha1-adrenergic receptors and their inhibitors in lower urinary tract symptoms and benign prostatic hyperplasia. J Urol. 2004; 171: 1029-1035.

5. Nickel JC, Sander S, Moon TD. A meta-analysis of the vascular safety profile and efficacy of alpha-adrenergic blockers for symptoms related to benign prostatic hyperplasia. Int J Clin Pract. 2008; 62: 1547-1559.

6. Mirone V, Sessa A, Giuliano F, et al. Current benign prostatic hyperplasia treatment: impact on sexual function and management of related sexual adverse events. Int J Clin Pract. 2011; 65: 1005-1013.

7. Giuliano F. Impact of medical treatments for benign prostatic hyperplasia on sexual function. BJU Int. 2006; 97 Suppl 2: 34-38.

8. [Internet] US Food and Drug Administration. Adverse Event Reporting System (AERS). http://www.fda.gov/Drugs/GuidanceCompliance RegulatoryInformation/Surveillance/AdverseDrugEffects/default.htm

9. Evans SJ, Waller PC, Davis S. Use of proportional reporting ratios (PPRs) for signa generation from spontaneous adverse drug reaction reports. Pharmacoepidemiol Drug Saf. 2001; 10: 483-486.

10. van Puijenbroek EP, Bate A, Leufkens HG, et al. A comparison of measures of disproportionality for signal detection in spontaneous reporting systems for adverse drug reactions. Pharmacoepidemiol Drug Saf. 2002; 11: 3-10.

11. Bate A, Lindquist M, Edwards IR, et al. A Bayesian neural network method for adverse drug reaction signal generation. Eur J Clin Pharmacol. 1998; 54: 315-321.

12. Szarfman A, Machado SG, O'Neill RT. Use of screening algorithms and computer systems to efficiently signal higher-than-expected combinations of drugs and events in the US FDA's spontaneous reports database. Drug Saf. 2002; 25: 381-392.

13. Bate A, Evans SJ. Quantitative signal detection using spontaneous ADR reporting. Pharmacoepidemiol Drug Saf. 2009; 18: 427-436.

14. Hauben M, Reich L. Drug-induced pancreatitis: lessons in data mining. Br J Clin Pharmacol. 2004; 58: 560-562.

15. Almenoff J, Tonning JM, Gould AL, et al. Perspectives on the use of data mining in pharmaco-vigilance. Drug Saf. 2005; 28: 981-1007.

16. Almenoff JS, Pattishall EN, Gibbs TG, et al. Novel statistical tools for monitoring the safety of marketed drugs. Clin Pharmacol Ther. 2007; 82: 157-166.

17. Hauben M, Bate A. Decision support methods for the detection of adverse events in post-marketing data. Drug Discov Today. 2009; 14: 343-357.

18. Sakaeda T, Tamon A, Kadoyama K, et al. Data mining of the public version of the FDA Adverse Event Reporting System. Int J Med Sci. 2013; 10(7):796-803.

19. [Internet] Pharmaceuticals and Medical Devices Agency. International Conference on Harmonisation of Technical Requirements for Registration of Pharmaceuticals for Human Use. http://www.pmda.go.jp/ ich/ich_index.html

20. [Internet] Maintenance and Support Services Organization. Medical Dictionary for Regulatory Activities. http://www.meddramsso.com/

21. Rosen R, Seftel A, Roehrborn CG. Effects of alfuzosin $10 \mathrm{mg}$ once daily on sexual function in men treated for symptomatic benign prostatic hyperplasia. Int J Impot Res. 2007; 19: 480-485.
22. Kirby RS, O'Leary MP, Carson C. Efficacy of extended-release doxazosin and doxazosin standard in patients with concomitant benign prostatic hyperplasia and sexual dysfunction. BJU Int. 2005; 95: 103-109.

23. Demir O, Ozdemir I, Bozkurt O, et al. The effect of alpha-blocker therapy on erectile functions in patients with lower urinary tract symptoms due to benign prostatic hyperplasia. Asian J Andol. 2009; 11: 716-722.

24. Yokoyama T, Hara R, Fukumoto K, et al. Effects of three types of alpha-1 adrenoreceptor blocker on lower urinary tract symptoms and sexual function in males with benign prostatic hyperplasia. Int J Urol. 2011; 18: 225-230.

25. Kaplan SA, Gonzalez RR, Te AE. Combination of alfuzosin and sildenafil is superior to monotherapy in treating lower urinary tract symptoms and erectile dysfunction. Eur Urol. 2007; 51: 1717-1723.

26. Kim MK, Cheon J, Lee KS, et al. An open, non-comparative, multicentre study on the impact of alfuzosin on sexual function using the Male Sexual Health Questionnaire in patients with benign prostatic hyperplasia. Int J Clin Pract. 2010; 64: 345-350.

27. McConnell JD, Roehrborn CG, Bautista OM, et al. The long-term effect of doxazosin, finasteride, and combination therapy on the clinical progression of benign prostatic hyperplasia. N Engl J Med. 2003; 349: 2387-2398.

28. Lepor H. Phase III multicenter placebo-controlled study of tamsulosin in benign prostatic hyperplasia. Urology. 1998; 51: 892-900.

29. Masumori N, Tsukamoto T, Iwasawa A, et al. Ejaculatory disorders caused by alpha- 1 blockers for patients with lower urinary tract symptoms suggestive of benign prostatic hyperplasia: comparison of naftopidil and tamsulosin in a randomized multicenter study. Urol Int. 2009; 83: $49-54$.

30. Song $\mathrm{SH}$, Son $\mathrm{H}$, Kim KT, et al. Effect of tamsulosin on ejaculatory function in BPH/LUTS. Asian J Androl. 2011; 13: 846-850.

31. Yu HJ, Lin AT, Yang SS, et al. Non-inferiority of silodosin to tamsulosin in treating patients with lower urinary tract symptoms (LUTS) associated with benign prostatic hyperplasia (BPH). BJU Int. 2011; 108: 1843-1848.

32. MacDiarmid SA. Combination antimuscarinics and alpha-blockers for benign prostatic hyperplasia. Curr Urol Rep. 2008; 9: 265-271. 